\title{
Marambiré como Patrimônio Cultural e Instrumento de Resistência para o Quilombo do Pacoval/Pará ${ }^{1}$
}

\author{
Marambiré como Patrimonio Cultural e Instrumento de Resistencia del \\ Quilombo del Pacoval/Pará \\ Marambiré as Cultural Patrimony and Intrument of Resistance of \\ Quilombo do Pacoval/Pará
}

Andréa Simone Rente Leão ${ }^{2}$

Girlian Silva de Souza ${ }^{3}$

Edilmar Santana Quaresma ${ }^{4}$

Joice Eliane Vasconcelos de Oliveira ${ }^{5}$

\begin{abstract}
Resumo
O presente ensaio introdutório tem o propósito de apresentar a dança do Marambiré como patrimônio cultural e de resistência do Quilombo do Pacoval e, portanto, um exemplo de organização cultural e social amazônica. A representação da dança do Marambiré é tida pelos quilombolas do Pacoval como a perpetuação da história de seus ancestrais, ao mesmo tempo, forma de manter viva sua cultura e origem. A origem das informações sobre o Quilombo do Pacoval, vem de autores locais, nacionais e entrevistas realizadas com os membros da dança do Marambiré - coordenação e componentes. Desta forma, conclui-se reafirmando que a ancestralidade negra, religiosidade, (re)existência cultural afro às intolerâncias sofridas e horizontalidade comunitária são características facilmente identificáveis nos comunitários do Quilombo do Pacoval, local onde a musicalidade se funde com a religião, expressando através da dança do Marambiré toda sua história de resistência cultural, social e política.
\end{abstract}

Palavras-Chave: Marambiré; Quilombo; Resistência, Protagonismo Feminino

\footnotetext{
${ }^{1}$ Artigo apresentado no Simpósio Temático (Saberes de desaprendizagens, Artes, Gênero e Sexualidade) durante o II Seminário Latino-Americano de Estudos em Cultura - SEMLACult em Foz do Iguaçu/PR, Brasil, 2018.

${ }^{2}$ Doutora em Ciências Sociais em Desenvolvimento, Agricultura e Sociedade - CPDA/UFRRJ; Economia, Instituto de Ciências da Sociedade - ICS, Universidade Federal do Oeste do Pará - UFOPA; Santarém, Pará, Brasil; asgrente@yahoo.com.br.

${ }^{3}$ Mestre em Planejamento do Desenvolvimento Sustentável - NAEA/UFPA; Economia, Instituto de Ciências da Sociedade - ICS, Universidade Federal do Oeste do Pará - UFOPA; Santarém, Pará, Brasil; gyr_gil@yahoo.com.br.

4 Estudante de Gestão Pública e Desenvolvimento Regional; Instituto de Ciências da Sociedade - ICS, Universidade Federal do Oeste do Pará - UFOPA; Santarém, Pará, Brasil; edquaresma@ globo.com.

5 Estudante de Gestão Pública e Desenvolvimento Regional; Instituto de Ciências da Sociedade - ICS, Universidade Federal do Oeste do Pará - UFOPA; Santarém, Pará, Brasil; joiceelianevasconcelos12@gmail.com.
} 


\begin{abstract}
Resumen
El presente ensayo introductorio, tiene el propósito de presentar la danza del Marambiré como patrimônio cultural y de resistência del Quilombo de Pacoval como un ejemplo de organización cultural y social amazónicas. La representación de la danza del Marambiré se tiene por los quilombolas de Pacoval, como la perpetuación de la historia de sus ancestros, al mismo tempo, como la forma de mantener viva su cultura y su origen. El origen de las informaciones sobre el Quilombo de Pacoval, viene de autores locales, nacionales y entrevistas realizadas con los miembros de la danza del Marambiré. Coordinación y componentes. De esta forma, se reafirma la conclusión que la ancestralidade negra, resistência cultural afro, a las intolerancia sufridas y horizontalidade comunitaria, son caractéristicas facilmente identificables en los comunitarios del Quilombo de Pacoval, local donde la musicalidade se funde con la religión, expresando a través de la danza del Marambiré toda su historia de resistencia cultural, social y politica.
\end{abstract}

Palabras claves: Marambiré; Quilombo; Resistencia, Protagonismo Feminino

\begin{abstract}
The actual introductory assay have the purpose of introduce the dance of Marambiré as cultural and resistance patrimony of Pacoval's Quilombo, so the place is an example of cultural and social organization of Amazon. The representation of Marambiré's dance is taken by the quilombolas as a perpetuation of their ancestors history, and a way to keep alive their culture. The origin of the informations about the Quilombo of Pacoval came from local authors and interviews made with de Marambiré's dance group. In this way it can be concluded that reaffirming the blackancestry, religious and existence the suffered intolerance and the community horizontality are features easily indentifiable on the residents of Pacoval's Quilombo, a place where the music mixes with the religion, expressing with Marambiré's dance all of your history of cultural, social and political resistance.
\end{abstract}

Keywords: Marambiré; Quilombo; Resistance, Women's Protagonism

\title{
1. Introdução
}

Este trabalho é fruto parcial de levantamentos realizados no âmbito do Projeto Formação Socioeconômica da Amazônia: estudos sobre desenvolvimento, sociedade e meio ambiente nos municípios de Alenquer e Belterra, Pará - Projeto Formaz. O Projeto Formaz, encontra-se em andamento na Universidade Federal do Oeste do Pará - UFOPA. Seu objetivo é integrar ensino e pesquisa, de forma interdisciplinar, para a realização de análises de processos históricos relacionados a formação socioeconômica e política dos municípios amazônicos Alenquer, Belterra e, mais recentemente, Mojuí dos Campos, buscando conhecer e entender as dinâmicas locais, regionais e a interação com o nacional e global. Dentro do contexto da pesquisa no município de Alenquer, o Quilombo do Pacoval emergiu como um exemplo típico de comunidade organizada, com uma história, sociedade e cultura diferenciada e representativa da realidade amazônica.

É importante ressaltar que a discussão apresentada leva em consideração a história, os saberes, a cultura e a arte de um povo. Uma arte representada pela dança do Marambiré, considerada um símbolo de resistência cultural e de um povo onde as protagonistas principais 
são as mulheres do Quilombo do Pacoval. Elas são as responsáveis por lutar e resistir contra o tempo, as gerações e, porque não dizer a "desaprendizagem” de uma cultura.

Uma cultura vista como um instrumento de resistência e perpetuação da história do povo negro. Ameaçada pelo tempo, modernidade e descaso político local em incentivar sua continuidade. Por isso, os estudos em Alenquer e, especificamente no Pacoval, visam de forma interdisciplinar, conhecer, divulgar, aprender e apreender sobre o Quilombo do Pacoval, sua trajetória, dinâmica e cultura onde, a dança do Marambiré é a mais importante representação de saberes, arte e gênero.

Neste sentido, o presente trabalho é um ensaio introdutório, com o propósito de apresentar a dança do Marambiré como patrimônio cultural e de resistência do Quilombo do Pacoval, exemplo de organização cultural e social amazônica. Para a comunidade do Pacoval, a dança do Marambiré simboliza a perpetuação e manutenção da sua cultura e ancestralidade. A origem das informações sobre o Quilombo do Pacoval, vem de autores locais, nacionais e entrevistas realizadas com os membros da dança do Marambiré - coordenação e componentes.

Este trabalho divide-se em quatro seções: a primeira é a Introdução, na segunda, dividida em duas subseções, estão as discussões sobre direito, identidade cultural, resistência como forma de apresentar o contexto onde se insere o debate e a apresentação da origem do Quilombo do Pacoval. A terceira seção traz o Marambiré, reconhecido como sinônimo de (re)existência cultural protagonizada pelas mulheres do Quilombo, onde se apresenta a dança do Marambiré e, alguns exemplos do protagonismo feminino em prol da referida dança e do Pacoval. Finaliza-se, na quarta seção, com as Conclusões.

Desta feita, tal artigo representa a primeira incursão dos autores no universo do Quilombo do Pacoval, e, um primeiro exercício de apreensão e discussão do tema. Isto justifica-se, devido ao impacto causado aos pesquisadores e a riqueza de informações, com subsídios suficientes para apresentar tal proposta como forma de divulgar uma experiência de pesquisa sociocultural num contexto amazônico. 


\title{
2. Do Mocambo ao Quilombo do Pacoval: as trajetórias de resistência de um movimento através de sua cultura
}

\subsection{Sobre a Categoria Quilombo e suas inferências}

Ante a intensa complexificação do processo de globalização e consequente avanço do ideário neoliberal - fenômenos producentes de estratégias cada vez mais elaboradas de colonialismo, dominação, exclusões sociais e de expulsões (WOLKER, 2007; SASSEN, 2016), induz-se à reflexão acerca das estratégias de resistência das sociedades locais. Neste sentido, Sassen (2016, p. 09), esclarece que "algumas formas de conhecimento e inteligência que respeitamos e admiramos muitas vezes estão na origem de longas cadeias de transação que podem terminar em simples expulsões". Desta forma,

\begin{abstract}
Impõe- se repensar a capacidade de resistência e de articulação da sociedade civil, o retorno dos sujeitos históricos e a produção da juridicidade a partir do viés criativo da pluralidade de fontes normativas. Certamente que a constituição de uma cultura jurídica pluralista e democrática, fundada nos valores do poder social compartilhado está necessariamente vinculada aos critérios de uma nova legitimidade. A força dessa eficácia passa, antes de tudo, pela capacidade de luta e de criação dos atores políticos envolvidos e pela satisfação de suas necessidades e reivindicações (WOLKER, 2007, p. 95).
\end{abstract}

Por conseguinte, os movimentos sociais por reconhecimento de identidades coletivas, utilizam estratégias de luta pelo direito formal à perpetuação das suas práxis sociais - que se materializam nas expressões artístico-culturais, nas práticas e saberes tradicionais, nos critérios de gêneros e na relação cosmológica com a natureza, que dita o modo de apropriação dos recursos naturais (ALMEIDA, 2008; DUPRAT, 2007; SOUZA; PEZZUTI, 2017). Em outras palavras, busca-se a aceitação por parte do campo jurídico formal acerca do caráter pluricultural e multiétnico das sociedades para a construção do campo jurídico do "direito étnico", permitindo que o direito seja pensado a partir da situação vivenciada pelos povos e comunidades tradicionais, superando-se, assim, os esquemas jurídicos pré-concebidos (DUPRAT, 2007). Como reflexo da luta dos movimentos de identidades coletivas, a categoria "tradicional" atualmente apresenta-se como operativo e reivindicativo de direitos, dinâmica de mobilização frente aos conflitos sociais nas áreas ocupadas por esses povos.

O critério político-organizativo sobressai combinado com uma "política de identidades", da qual lançam mão os agentes sociais objetivados em movimento para fazer frente aos seus antagonistas e aos aparatos de estado. Aliás, foi exatamente este fator identitário e todos os outros fatores a ele subjacentes, que levam as pessoas a se agruparem sob uma mesma expressão coletiva, a declararem seu pertencimento a um povo ou a um grupo, a afirmarem uma territorialidade específica e a encaminharem organizadamente demandas face ao Estado, exigindo o 
reconhecimento de suas formas intrínsecas de acesso à terra [...] (ALMEIDA, 2008, p.30).

Desta forma, o amparo jurídico-formal é conditio sine qua non para a perpetuação do patrimônio cultural desses povos, sintetizando a importância da mobilização política. As teorias do Pluralismo Jurídico demonstram que o direito produzido pelo Estado não é o único, que está presente na sociedade civil, nas lutas sociais. É necessário reconhecer a existência de múltiplas identidades étnico-culturais, dotadas de valores plurais, específicos e coletivos, como uma estratégia emancipatória (WOLKER, 2007).

Esta perspectiva alude à significância do conceito de "territorialidade específica" e à luta da comunidade do Quilombo do Pacoval pela preservação e perpetuação da sua expressão cultural como condição de (re)existência frente aos conflitos gerados tanto pela discriminação associada às categorias mocambo/quilombo, quanto pela pressão gerada pelos interesses do capital sobre os recursos naturais presentes naquele território. Neste sentido, a expressão "(re)existência" alude à natureza política e reivindicatória do direito de perpetuação enquanto povo, cujo patrimônio imaterial, os particulariza. Ressalta-se que o sentimento de pertença que os congrega em uma comunidade não se resume apenas às expressões culturais - nas quais, o Marambiré se destaca.

O sentimento de pertença e autodenominação enquanto "quilombolas" não pode ser dissociado das suas relações de reprodução socioeconômicas dentro daquele lugar específico. E nesta perspectiva, o conceito de território não qualifica apenas o espaço delimitado geograficamente, mas às relações simbólicas e cosmológicas que estruturam a sua práxis social (ALMEIDA, 2008; SOUZA; PEZZUTI, 2017). Isto posto, este ensaio encontra-se dentro dessa lógica que qualifica o Marambiré como uma expressão cultural de um povo e um instrumento de resistência às diversas estratégias de colonialidade.

A autodenominação "quilombolas" não pode ser dissociado das relações de reprodução socioeconômicas dentro daquele lugar específico. Portanto, o termo "território" compreende para além do espaço delimitado geograficamente, às relações simbólicas e cosmológicas que estruturam a sua práxis social (ALMEIDA, 2008; SOUZA; PEZZUTI, 2017). A categoria "quilombo/quilombola" é indicativa de luta por direitos, posto que segundo a Constituição Federal de 1988, Ato das Disposições Constitucionais Transitórias, artigo $\mathrm{n}^{\circ} 68$, “Aos remanescentes das comunidades de quilombos que estejam ocupando suas terras, é reconhecida a propriedade definitiva, devendo o Estado emitir-lhes os títulos respectivos" (BRASIL, 1988). 
Desta forma, a categoria "quilombo", refere-se às comunidades remanescentes de fugitivos da escravidão negra no Brasil. Sua territorialidade é um complexo de processos identitários de luta por reconhecimento do direito à cidadania (GOMES, 2015). Os termos mocambo e quilombo, são frequentemente utilizados como sinônimos para referenciar essas comunidades.

Historicamente, estes termos possuíram outros significados. Segundo Gomes (2015), tais termos são originários da África Central, e no Brasil, referiam-se aos acampamentos improvisados pelos negros tanto para fins de guerrilhas como para o aprisionamento de escravizados. No século XVII, o termo quilombo estava associado aos rituais de iniciação dos guerreiros Imbangalas (jagas). Mocambo ou mukambu, nas línguas kimbundu e kicongo, significava “[...] pau de fieira, tipo de suportes com forquilhas utilizadas para erguer choupanas nos acampamentos [...]" (GOMES, 2015, p. 04).

No Brasil, desde o início da colonização, estas comunidades foram denominadas mocambos e mais tarde, quilombos, que eram constituídas por negros escravizados, fugitivos do modo de produção escravagista. Segundo Gomes (2015), o primeiro registro oficial de um mocambo no Brasil, data de 1575, formado na Bahia. Cumpre destacar que no modo de produção escravagista, os negros escravizados eram vistos como capital imobilizado e tratados como peças cujo valor monetário é um sinal da abastança de seu possuidor (FURTADO, 2005).

Por conseguinte, as fugas de negros escravizados representavam prejuízos para a aristocracia, e representava um ato de extrema rebeldia contra o sistema escravocrata, era também, uma demonstração de organização e resistência. Conforme Gomes (2015, p. 04) esclarece:

Fugir era uma ação muitas vezes planejada, não significando um simples ato de desespero diante de castigos. Havia ocasiões consideradas propícias e muitas escapadas coletivas foram antecedidas de levantes ou motins. Em 1585, há indicações de que os fugidios que estabeleceram um mocambo tinham participado antes de uma revolta no recôncavo da Bahia. Estudos mais recentes sugeriram que o aumento das fugas de escravos indígenas e africanos no Nordeste foi ocasionado também pelos movimentos milenaristas - Santidades - nas últimas décadas do século XVI. Períodos de conflitos coloniais foram também determinantes para o aumento das fugas - principalmente as coletivas - e o crescimento dos quilombos.

Logo, as fugas causavam prejuízos para a aristocracia, e representavam atos de extrema rebeldia, organização e resistência contra o sistema escravocrata. Desta forma, os quilombos representam uma prática decolonial - posto que "a decolonialidade consiste também numa prática de oposição e intervenção que surgiu no momento em que o primeiro sujeito colonial do sistema moderno/colonial reagiu contra os desígnios imperiais que se 
iniciou em 1492” (COSTA-BERNADINO; GROSFOGUEL, 2016, p. 17). Na próxima seção apresentaremos o Quilombo do Pacoval e o Marambiré como sinônimo de (re)existência e cultura.

\subsection{Sobre o Quilombo do Pacoval}

A origem do Quilombo do Pacoval se assemelha com a história de muitos quilombos brasileiros que emergem através de fugas dos negros escravizados, maltratados pelos donos de fazenda. Sendo esta história iniciada nos ditos anos da escravidão do Brasil, os registros escritos são escassos, originado de muitas versões, fruto de relatos orais dos primeiros moradores do Quilombo do Pacoval à historiadores e pesquisadores que, ao longo dos anos vem estudando e registrando a história da comunidade como Teixeira (1989), Funes (1995), Azevedo (2002) e Queiroz (2011, 2017).

Segundo Queiroz $(2011 ; 2017)$, um negro escravo de nome Alexandre organizou uma fuga de escravos da fazenda de Maria Macambira, situada no município de Santarém/Pará. Conforme Teixeira (1989) tal fuga tinha por justificativa os mais diversos castigos físicos e maus tratos que sofriam na referida fazenda, como por exemplo, "o retalhar das nádegas". Os negros em fuga e liderados por Alexandre utilizaram o rio Amazonas, passando pelo município de Monte Alegre, os rios Maicurú, Curuá, Cuminã e, seguindo o curso deste último, fundaram o Quilombo São Benedito.

Uma rota nada fácil devido às dificuldades naturais do lugar, como também à perseguição aos escravos fugidos pelos capangas e pela própria Maria Macambira (TEIXEIRA, 1989). Para Teixeira (1989), a desistência da perseguição aos escravos só chegou ao fim quando Maria Macambira chegou ao Igarapé do Acari e, assustada com a violência das águas do mesmo teria chamado de Igarapé do Inferno e desistido de sua perseguição aos escravos fugidos. No Quilombo São Benedito, os escravos fugidos ficaram um período, se instalaram e com os recursos naturais que extraíam do lugar (banana, babaçu, urucuri e castanhas) tinham as bases de sua subsistência, tornando-se autossuficientes, fazendo até suas roupas com o algodão que plantavam na área (QUEIROZ, 2011).

Com o tempo, a necessidade de consumo de outros produtos os levou à prática do escambo. O comerciante e Major, que vivia na região do Paraná de Alenquer, Martins Beata, destacado por Queiroz (2011; 2017), começou a fazer comércio, via escambo, com os quilombolas. Esse contato comercial possibilitou aos quilombolas, através de seu líder 
Alexandre, doze anos antes do fim da escravidão, buscar as autoridades políticas do município de Alenquer e da capital do estado - Belém - para o reconhecimento do quilombo e a liberdade dos que lá viviam - aproximadamente 150 negros fugidos (QUEIROZ, 2017).

A partir dessas articulações, o líder quilombola chegou a ir à Belém, conseguindo das autoridades paraenses o reconhecimento público do quilombo como um lugar livre onde "[...] os negros poderiam viver tranquilos [...]" (QUEIROZ, 2017, p. 19), conseguindo do imperador D. Pedro II, em 1877, a doação de terras do município de Alenquer, onde fundaram o Quilombo do Pacoval, nas matas do rio Curuá. Deste importante momento histórico, algo relatado por entrevistados de Teixeira (1989, p. 25), foi a frase de D. Pedro II ao entregar o documento de doação das terras: “Tá aqui, não vão deixar caboco tomar de vocês". Para Funes (1995, p. 324), com relação aos primeiros negros que se estabeleceram no Pacoval:

[...] os agora ex-quilombolas constituíram um novo espaço, dessa vez nas águas mansas e sem perigo das expedições punitivas, embora ali por certo vivessem outros quilombolas, novos e antigos, que haviam conseguido escapar às medidas "suasórias" de 1876 e aos ataques indígenas de 1877. Essa comunidade negra tornava-se, portanto, mas um lugar onde o escravo podia buscar a invisibilidade de sua condição social, valendo-se da categoria de ex-mocambeiro.

E, assim retomando seus modos e estilo de vida, trabalhando, como relatado acima, para sua autossubsistência. Desse período, ficam as marcas e história da luta pela liberdade e direito a um lugar para viver. Como diz Funes (1995, p. 324):

Pacoval dos mocambeiros, que um dia foram escravos de Maria Macambira e de outros senhores do Baixo Amazonas; que romperam com a escravidão, embrenharam-se nas matas do Curuá, nos altos dos rios, e constituíram seus espaços de liberdade onde tantos outros nasceram.

Sendo esta sensação de "espaço de liberdade" que embalou e embala até os dias de hoje as gerações e gerações que permanecem no Pacoval.

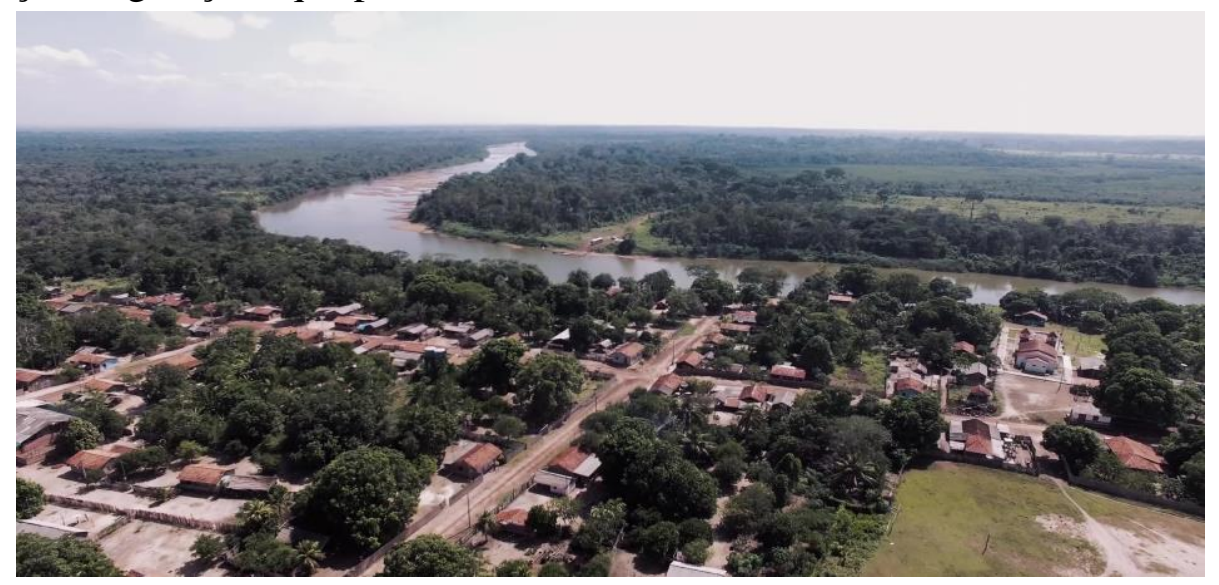

Foto 01: Comunidade do Quilombo do Pacoval.

Fonte: Documentário "Marambiré”, 2016.

Pacoval, representado na Foto 01, portanto, é uma comunidade de remanescentes de quilombo, reconhecida e titulada, respeitando a Constituição Federal de 1988, artigo nº 68 e 
outras leis originadas da referida Constituição, garantindo $\mathrm{o}$ direito às terras aos remanescentes de quilombos. O Título de Reconhecimento de Domínio No 001/96 que a União, via o Instituto de Colonização e Reforma Agrária - INCRA, outorgaram à Associação da Comunidade Remanescente de Quilombo do Pacoval de Alenquer - ACONQUIPAL/PA data de 20 de novembro de 1996.

Neste documento, a União reconhece o domínio da ACONQUIPAL/PA sobre 7.472,8790 hectares de área da zona rural, situada na gleba Mamiá, do município de Alenquer (INCRA, 1996). A ACONQUIPAL/PA foi criada em 1989 tendo como primeiro presidente o Sr. Roberto Carlos Leitão que assinou pela Associação o título de reconhecimento de domínio citado acima. Esta Associação, até hoje ativa, vem trabalhando e representando o Quilombo do Pacoval. (COSTA; CARIPUNA, 2015).

Foi criada em função de ser uma das condições para o reconhecimento e garantias de direitos para os habitantes do Pacoval. Desta forma, legalizar a ACONQUIPAL/PA foi um importante passo na obtenção do título e de outros programas do governo federal para a comunidade, mantendo-se hoje com aproximadamente 250 famílias (COSTA; CARIPUNA, 2015).

O importante ao estudar e vivenciar experiências de convivência com espaços como o Quilombo do Pacoval é poder reconhecer a importância do resgate histórico via sua organização social, mas, também, via sua cultura. O Quilombo do Pacoval até hoje busca resistir e coexistir com as mudanças socais, buscando manter viva suas principais referências culturais, na qual o grande destaque vai para a dança do Marambiré, tema deste artigo e da próxima seção.

\section{Marambiré Sinônimo de (Re)existência e Cultura do Quilombo do Pacoval}

\subsection{A Dança do Marambiré}

Uma das principais expressões culturais do Quilombo do Pacoval é a dança do Marambiré. Segundo Azevedo (2002, p. 54), o Marambiré é um dos rituais de raízes africanas tradicionais da Amazônia, considerado “[...] sagrado, dinâmico, alegre, sedutor e cheio de evoluções". É uma importante manifestação folclórica de (re)existência negra, onde se celebra a memória dos ancestrais africanos que foram arrancados de sua origem natural. 
No documentário, intitulado, Marambiré de $2016^{6}$, realizado através do Grupo Lamparina Filmes e apoiado pelo Ministério da Cultura, um componente/entrevistado da dança do Marambiré, fala que os avós dele contavam que o Marambiré é uma dança religiosa que veio trazida pelos negros fugitivos. Tal dança era uma forma de agradecer pelo êxito das fugas que os escravizados tiveram.

Com a fixação desses negros em terras do atual Pacoval, plantações foram realizadas e no final de cada ano, após boas colheitas, essa dança e suas músicas eram utilizadas para agradecer. Por isso, os cânticos seguem uma ordem como o acolhimento, agradecimento e despedida. "Si Marambiré não foi inventado aqui, não. Si Marambiré veio trazido da África. Foi da África que veio o Marambiré", como bem menciona o quilombola João Preguelo durante o referido documentário.

A origem da palavra Marambiré, segundo o historiador Eurípedes Funes, um dos entrevistados do documentário pode ser uma junção da sonoridade das palavras Maramba e Aiwé. Segundo o entrevistado Funes, sua pesquisa foi realizada através de levantamento de registros pós mortis. A partir desses levantamentos, descobriu que a maioria dos quilombolas dessa região do Pacoval foram trazidos da região Congo-angolana.

Com esta descoberta, o historiador Funes, realizou pesquisas em dicionários da cultura bantofônico até chegar nas palavras companheiros e festa, respectivamente. Assim como a palavra Marambiré, outras palavras estão presentes nos cantos dessa dança sem que os próprios quilombolas saibam de seus significados. Tiãmba, puxinga e currimboque são exemplos de palavras presentes no canto do Marambiré que tem seus significados desconhecidos. Os quilombolas também chamam o Marambiré de Sangambira.

Marambiré ou Sangambira, segundo Teixeira (1989, p. 34, grifo da autora) foram reconhecidas como danças folclóricas do Pará pelo historiador Vicente Salles que "[...] faz menção ao Marambirê (e não Marambiré, como conhecemos hoje), tendendo qualificar a denominação como título de nobreza (folclórico) [...]”. Portanto, não havendo uma, mas, algumas pistas do significado da palavra Marambiré.

Mais do que o significado da palavra, para os olhos de quem comtempla tal dança, concorda-se em parte, com a afirmação de Figueiredo (1995, p. 210):

O Marambiré é, para um analista de fora da comunidade, apenas mais um ritual afrobrasileiro, com caracteres dramático-religiosos, dentre tantos existentes no Brasil. Contudo, para o nativo do Pacoval, o Marambiré transcende os domínios do folclore

\footnotetext{
${ }^{6}$ Como foi um dos trabalhos mais atuais sobre a Dança do Marambiré e, compila todos os outros estudos sobre a referida dança, estamos utilizando o mesmo como fonte principal para descrever tal dança, ao mesmo tempo que utilizamos autores e nossas próprias percepções sobre o que vimos da performance da Dança.
} 
e assume o significado da própria memória social da vila, que, através de sua tradição oral e visual, transmite aspectos referentes à saga do negro na Amazônia e, mais do que isto, revela aos mais novo s a história de seus antepassados.

O concorda-se "em parte" com a citação acima advém do fato de acreditar que, até para os olhos de "um analista de fora" tal dança remete à emoções e vislumbres de algo belo, simples e forte. Emanam sensações de admiração e contemplação de algo que transcende o conhecido. Não é à toa que o Marambiré “é um patrimônio histórico, social, político, cultural, filosófico e religioso" (AZEVEDO, 2002, p. 54) do Quilombo do Pacoval, "que representa todo o sincretismo cultural e religioso característico da região [...]" (AZEVEDO, 2002, p. 55).

Sua formação tradicional contém 36 componentes, originalmente, podendo ser dançado por mais pessoas. São o Rei do Congo, Rainha Mestra, Rainhas Auxiliares, Valsares, Valsares Auxiliares, Caixeiros, Pandeiristas, Frentistas, Cabeçários e Contra Mestre, cada um dos componentes com uma função particularizada. Percebe-se a formação de uma grande corte que durante a apresentação do Marambiré no Pacoval depositam suas coroas, capacetes e os instrumentos de percussão que dão ritmo à dança no altar da Igreja de Santo Antônio, padroeiro da comunidade (TEIXEIRA, 1989), como aparece na Foto 02.

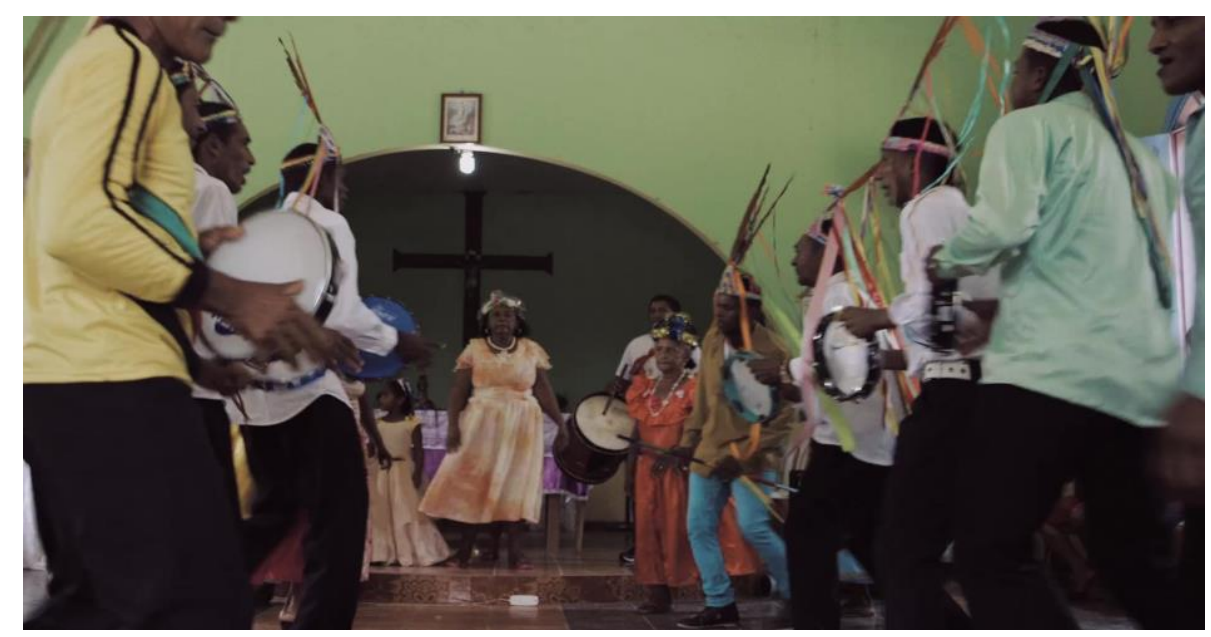

Foto 02: Dança do Marambiré na Igreja de Santo Antônio - Pacoval. Fonte: Acervo Projeto Formaz, 2018

A dança do Marambiré tem um período específico para ser apresentada: o ciclo dos festejos de Natal, seguindo na Epifania (6 de janeiro), dia da festa de São Benedito e terminando no dia 20 de janeiro, dia de São Sebastião. Poucas são as igrejas onde a dança e os cantos do Marambiré são permitidos. Em tempos pretéritos, a dança do Marambiré era realizada às escondidas dos padres pois estes não tinham permissão da Igreja para tais manifestações (FIGUEIREDO, 1995). 
Atualmente a dança do Marambiré ${ }^{7}$ tem suas apresentações dentro de Igrejas das várias cidades da região, como representada na Foto 02, quebrando-se paradigmas centenários no que tange as apresentações da dança dos negros do Pacoval. Para os personagens representados na dança do Marambiré, São Benedito é o dono do Marambiré, comprovado através das ladainhas cantadas durante a dança (FIGUEIREDO, 1995). Segundo a coordenadora do Marambiré ${ }^{8}$ do Quilombo do Pacoval, "o ritual apresenta uma indumentária rica de criatividade na qual é feita de simples objetos do nosso cotidiano".

A dança é seguida por música própria para cortejo, com um total de vinte e três cânticos bem marcados, ritmados e animados que louvam o Menino Deus, a Santíssima Trindade, a virgem Maria, São Benedito (intitulados pelos quilombolas como o santo dos pretos) e finalmente a Santo Antônio, padroeiro da comunidade do Pacoval. O cortejo real tem duas embaixadas bem definidas: a primeira embaixada é da realeza onde estão o Rei e Rainha do Congo seguido pelas sete rainhas auxiliares. A segunda embaixada é a dos valsares que simbolizam os vassalos reais e o Contra Mestre (FIGUEIREDO, 1995).

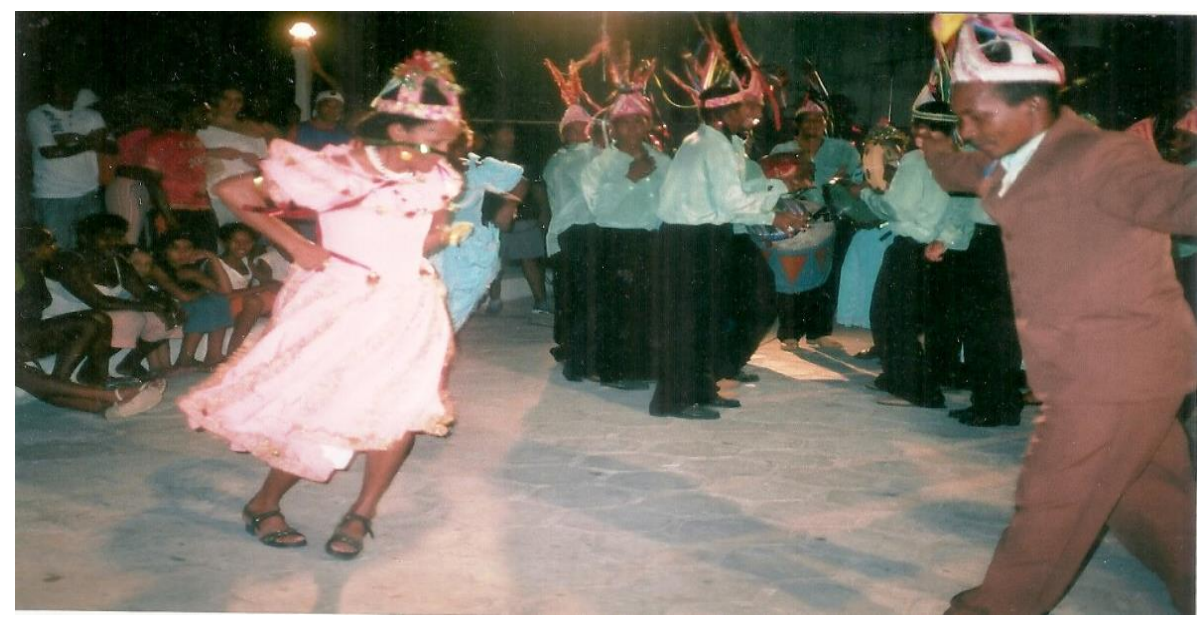

Foto 03: Dança do Marambiré representação das coroas Fonte: Blog Anamani, 2018.

Imprescindível são as coroas dos dançarinos, cada uma com sua especificidade que marcam claramente qual o papel do dançarino no rito do Marambiré: a do Rei do Congo apresenta fitas coloridas, um triângulo na parte frontal e tiras na parte superior; as coroas das Rainhas apresentam tiras na parte superior, fitas e flores. As dos Valsares trazem em seus capacetes somente as fitas multicoloridas, como ilustra a Foto 03. Tal diferenciação, como ilustra na fotografia abaixo, nos mostra claramente a importância da figura do Rei do Congo

\footnotetext{
${ }^{7}$ A dança do Marambiré mais tradicional e, reconhecida como Patrimônio Artístico e Cultural do Pará é a do Quilombo do Pacoval, porém, outros quilombos da área da Calha Norte também apresentam tal dança.

${ }^{8}$ Entrevista com a Coordenação do Marambiré, concedida em 16/02/2018, aos autores desse artigo.
} 
na dança do Marambiré, visto que sua coroa incorpora tanto características das coroas masculinas e femininas em uma só (FIGUEIREDO, 1995).

Um dos pontos altos da dança é o momento em que o casal de reis oferecem suas coroas a um casal que está assistindo à dança para assim evoluírem dentro do grupo, sendo inaceitável recusar tal oferenda. A recusa é considerada sinônimo de desfeita para com o rito do Marambiré. $\mathrm{O}$ ato do ofertório das coroas marca o único instante da presença de pessoas que não fazem parte do cortejo do Marambiré pode se misturar com os dançantes das embaixadas real e dos valsares (FIGUEIREDO, 1995).

Ainda segundo esse autor:

O Marambiré encerra-se com a união dos presentes cantando o Vamo Simbora, um canto que sintetiza muitas questões referentes aos significados ritualísticos do Cordão de São Benedito - o santo está de volta à sua morada, o que evidencia que a festa acabou e que todos, como que num movimento cíclico, devem voltar à vida normal e ao trabalho. [...]. (FIGUEIREDO, 1995, p. 222)

Portanto, a dança do Marambiré é uma representação da identidade dos quilombolas. Para a Rainha Mestra do Marambiré: “O Marambiré é tudo, tá no sangue, tá na alma, tá em tudo [...] Se hoje nós tem o título é o Marambiré [...] tudo em nós é Marambiré"`. Tal é sua importância que, em 2008, foi reconhecido como Patrimônio Cultural e Artístico do Pará pela Lei 7.113 de 19 de março de 2008, como “expressão artística e cultural do município de Alenquer" (PARÁ, 2008).

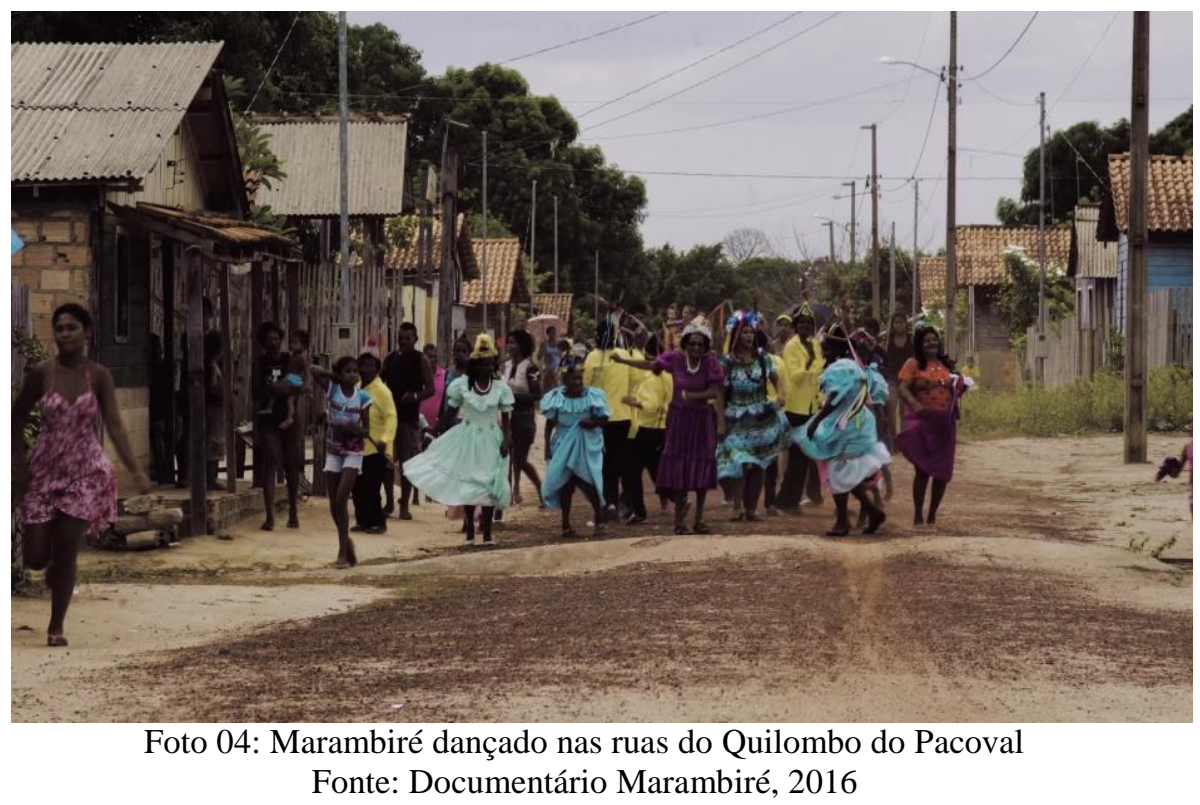

A dança do Marambiré, como visto na Foto 04, é um registro da ancestralidade africana que foi escravizada na região, sendo uma dança representativa da relação de um povo

\footnotetext{
${ }^{9}$ Entrevista com a Rainha Mestra do Marambiré, em 16/02/2018.
} 
sua ancestralidade e seu território. Os saberes são transmitidos através da oralidade - por seus pais, avós e bisavós. Os antigos repassam a tradição às novas gerações através do Marambiré Mirim como forma de (re)existência - fortalecendo e encorajando-os a enfrentar o racismo de alguns dos munícipes de Alenquer que, historicamente vem rejeitando a comunidade.

Recentemente, a comunidade criou o "Marambiré das Mulheres" com suas Rainhas Mestras, Rainhas do Congo e "a" Rei do Congo, e suas respectivas valsares - demonstração tanto da força da mulher negra na disseminação da cultura, quanto as características matriarcais do referido Quilombo, como se verá na próxima subseção.

\subsection{O Protagonismo das Mulheres do Pacoval através do Marambiré das Mulheres e de outras Ações dentro do Quilombo}

Nas comunidades quilombolas são as mulheres que cuidam da família e do quilombo como um todo. Por meio da organização e sensibilidade, elas acabam tomando conta de tudo. Muitas assumem a liderança das associações, outras quaisquer outras funções, apenas para não deixar de ajudar (ONU MULHERES, 2017).

Essa atuação das mulheres negras quilombolas é uma herança histórica deixada pelas ancestrais do primeiro quilombo conhecido. Quando Zumbi e os homens do Quilombo dos Palmares saiam para trabalhar, Acotirene ${ }^{10}$, Dandara ${ }^{11}$ e outras as mulheres, assumiam a liderança nas comunidades trabalhando nos roçados, no cuidado dos filhos, nas tradições e nas manifestações culturais. Portanto, as mulheres quilombolas carregam consigo saberes tradicionais importantes para organização social, produtiva e estratégica de resistência negra. (ONU MULHERES, 2017).

Isto manifestado até os dias atuais nas comunidades remanescentes de Quilombo, como o Quilombo do Pacoval. As mulheres quilombolas do Pacoval representam muito bem a força e resistência do seu território. São elas que desde o princípio lutaram pelo reconhecimento do quilombo e até hoje continuam lutando, não só pela garantia de direitos aos comunitários, mas também pela permanência das manifestações culturais deixada pelos antepassados, a exemplo da dança do Marambiré.

\footnotetext{
10 Segundo Gonçalves (2017, p. 01), Acotirene é: “Considerada matriarca no Quilombo dos Palmares e conselheira dos primeiros negros refugiados na Cerca Real dos Macacos".

${ }^{11}$ Esposa de Zumbi, Dandara foi uma das "lideranças femininas negras que lutou contra o sistema escravocrata do século XVII e auxiliou Zumbi quanto às estratégias e planos de ataque e defesa do quilombo" (FUNDAÇÃO CULTURAL PALMARES, 2014, p. 1).
} 
Por mais que o Pacoval tenha como presidente um homem, são as mulheres as maiores articuladoras das atividades realizadas na comunidade. Em entrevista com as principais personagens da Dança do Marambiré, em 16 de fevereiro de 2018, obteve-se a informação de que a dança do Marambiré é coordenado, atualmente, por uma mulher. Dona Telma, a coordenadora da Dança do Marambiré, pode ser considerada como uma guerreira que luta e enfrenta os obstáculos geracional e administrativo da permanência dessa tradição cultural e religiosa.

O Marambiré das Mulheres, dançado como o Marambiré habitual, porém composto apenas por mulheres, foi criado em 2017, com suas Rainhas Mestras, Rainhas do Congo e "a" Rei do Congo, e suas respectivas valsares, é coordenado pela Dona Irene. As mulheres do Quilombo do Pacoval criaram esta outra forma de resistência para demonstrar a importância das mulheres para o Quilombo e o quanto merecem reconhecimento, por seu poder de inovar e convencer a comunidade da importância do Marambiré e de não deixa-lo perecer mesmos que isso signifique recriá-lo como é o caso do Marambiré de Mulheres ${ }^{12}$.

Ademais, as quilombolas do Pacoval organizam também as atividades da semana da Consciência Negra, articulando junto com os comunitários(as) os temas que devem ser expostos e discutidos durante esse período. A semana da Consciência Negra é trazida aqui como um exemplo de organização e articulação das mulheres quilombolas do Pacoval. Em entrevista com a Coordenadora do Marambiré, em 16/02/2018, ela nos conta que durante a semana da Consciência Negra, a comunidade realiza exposição de cartazes e palestras que possam informar os comunitários do Pacoval os seus direitos, tal como devem reagir aos atos de racismo que sofrem por parte dos munícipes de Alenquer.

Este é um diferencial importante do Pacoval que vale a pena frisar. Enquanto em alguns lugares ou até mesmo em outros quilombos se discute na semana da Consciência Negra as dificuldades, os preconceitos e as conquistas adquiridas do movimento, no Pacoval eles criam mecanismos que se transformam em ações de conscientização. Ensinando desde cedo como eles, enquanto quilombolas, devem enfrentar as práticas racistas e preconceituosas que irão encarar, bem como reagir a tal ato.

Essas e outras atividades são planejadas pelas mulheres que, além da organização das ações da comunidade, da dança do Marambiré Tradicional e do Marambiré das Mulheres, também organizam o Marambiré Mirim. Este, como forma de dá continuidade à tradição do Marambiré tendo em vista, segundo os relatos dos entrevistados de 16/02/2018, a

\footnotetext{
${ }^{12}$ Informações retiradas a partir da entrevista com a Rainha Mestra do Marambiré, em 16/02/2018.
} 
preocupação dos mais velhos com o fato das crianças não quererem mais dançar o Marambiré, por vergonha. Algo que, na comunidade foi fortalecido pelas ações dos vereadores do município de Alenquer, que decretaram que professores de fora do Pacoval, fossem lecionar no quilombo.

E, em momentos festivos como Festa Junina e Folclore, tais professores ensinavam para as crianças danças que valorizavam outras culturas, como por exemplo, dança portuguesa, distanciando as crianças de sua própria cultura, a dança do Marambiré. Diante deste episódio que começava a ser um problema para a manutenção do Marambiré, a coordenação da Dança, sob a liderança de uma mulher, lutou junto à justiça para que não viesse mais professores de fora para a comunidade do Pacoval. O Pacoval tinha pessoas capacitadas dentro da comunidade para assumir a educação na escola da Comunidade, que precisavam ser valorizadas em prol delas mesmos e de suas tradições.

Esta luta foi vencida pela comunidade que conta com professores locais e com o compromisso de manter viva a dança do Marambiré, ajudados pelas lideranças da referida Dança. Assim, logo após o ocorrido, a cultura tradicional foi retornando, as crianças voltaram a dançar o Marambiré, desta vez por meio do Marambiré Mirim, iniciativa formada pela força e determinação da mulher quilombola. Em suma, podemos perceber o quanto a atuação das mulheres no Pacoval é presente em virtude das características matriarcais que o mesmo carrega.

Embora o homem ainda leve todo o protagonismo dentro dos quilombos, são as mulheres que carregam o sinônimo de luta e resistência das comunidades remanescentes de quilombo, por meio do sustento dos recursos naturais, da organização social e da propagação dos conhecimentos ancestrais (ONU MULHERES, 2017). No Quilombo do Pacoval, isso não é diferente, a exemplo do que está sendo apresentado, a Dança do Marambiré como patrimônio cultural e instrumento de resistência de um povo, tem como protagonistas as mulheres. Mulheres que resistem para perpetuar uma das essências de sua história e, que resistem ao tempo buscando caminhos e motivações para manter o interesse das novas gerações pela cultura de seu povo.

\section{Conclusões}

Conclui-se reforçando e afirmando a observação in locu da força cultural e de resistência das pessoas do Quilombo do Pacoval, especialmente das mulheres que buscam manter a tradição através da dança do Marambiré, como expressão de uma comunidade que 
continua mantendo suas origens de geração em geração. Portanto, ancestralidade negra, religiosidade, (re)existência cultural afro às intolerâncias sofridas e horizontalidade comunitária são características facilmente identificáveis nos comunitários do Quilombo do Pacoval, local onde a musicalidade se funde com a religião através da dança do Marambiré. Nesta comunidade, percebe-se demonstrações de uma história de resistência cultural, social e política que precisam ser conhecidas e estudadas.

Neste sentido, a pesquisa que vem sendo desenvolvida no município de Alenquer tem sua importância no resgate da história, no reconhecimento de organizações sociais que buscam preservar sua cultura e modos de vida. Tal pesquisa continua em andamento e, portanto, esta conclusão é apenas introdutória. A continuidade da mesma, com certeza ampliará as percepções e discussões acerca da temática e do local.

Sua continuidade garantirá projetos futuros tanto no âmbito da pesquisa como da extensão onde a ampliação dos estudos terá como norte a história, os processos de desenvolvimento e as alternativas multiculturais estabelecidas na região, a exemplo do Quilombo do Pacoval e sua dança do Marambiré. Assim participar de eventos como o SEMLACult, só ampliou o conhecimento quanto ao tema, fortalecendo as ideias e ações pertinentes aos estudos no Quilombo do Pacoval.

\section{Referências}

ALMEIDA, A. W. B. de. Terra de Quilombo, Terras Indígenas, "Babaçuais Livre”, "Castanhais do Povo", Faixinais e Fundos de Pasto: terras tradicionalmente ocupadas. Manaus: PPGSCA: UFAM, 2008.

AZEVEDO, I. M. Puxirum: Memória dos Negros do Oeste Paraense. Belém: Editora IAP, 2002.

BLOG ANAMANI. Dança do Marambiré. Disponível em: https://blogmanamani.wordpress.com/2015/07/29/marambire-de-alenquer-para. $\quad$ Acesso: 28/12/2018.

BRASIL. Presidência da República. Constituição (1988). Constituição da República Federativa do Brasil de 1988. Disponível em: <http://www.planalto.gov.br/ccivil_03/constituicao/ constitui\% C3\%A7ao.htm>. Acesso em: 10 mai. 2018.

COSTA-BERNADINO, J.; GROSFOGUEL, R. Decolonialidade e perspectiva negra. Revista Sociedade e Estado, Brasília, v. 31, n. 01, p. 15-24, jan./abr. 2016.

COSTA, R. L. N.; CARIPUNA, R. E. As Festas da Ramada no Quilombo do Pacoval, Alenquer (1960-1970). 2015. 36 f. Trabalho de Conclusão de Curso (Licenciatura Integrada 
em História e Geografia) Instituto de Educação, Universidade Federal do Oeste do Pará, Alenquer, 2015.

DUPRAT, D. Prefácio. In: SHIRAISHI NETO, Joaquim (Org.). Direito dos Povos e das Comunidades Tradicionais no Brasil: declarações, convenções internacionais e dispositivos jurídicos definidores de uma política nacional. Manaus: UEA, 2007, s/n.

FIGUEIREDO, A. Um Natal de Negros: esboço etnográfico sobre um ritual religioso num quilombo amazônico. Revista de Antropologia, v. 02, n. 38, p. 207-238, 1995. Disponível em: https://doi.org/10.11606/2179-0892.ra.1995.111569. Acesso em: 28/12/2018.

FUNDAÇÃO CULTURAL PALMARES. Personalidades Negras - Dandara. 7 de julho de 2014. Disponível em: http://www.palmares.gov.br/? $\mathrm{p}=33387$. Acesso em: 25 de dezembro de 2018.

FUNES, E. A. "Nasci nas Matas nunca tive senhor": história e memória dos mocambos do Baixo Amazonas. 1995. 441 f. Tese (Doutorado em História Social) - Instituto de História, Universidade de São Paulo, 1995.

FURTADO, C. Formação econômica do Brasil. São Paulo: Companhia das Letras. $34^{\mathrm{a}}$ Ed. 2005.

GOMES, F. dos S. Mocambos e quilombos: uma história do campesinato negro no Brasil. $1^{\mathrm{a}}$ Ed. São Paulo: Claro Enigma, 2015.

GONÇALVES, P. 17 Mulheres Negras Brasileiras que Lutaram Contra escravidão. Portal Géledes. 10 de julho de 2017. Disponível em: https://www.geledes.org.br/17-mulheresnegras-brasileiras-que-lutaram-contra-escravidao/. Acesso em: 25 de dezembro de 2018.

INCRA. Título de Reconhecimento de Domínio/INCRA/N ${ }^{o}$ 001/96. Disponível em: cpisp.org.br/wp-content/uploads/2017/06/PACOVAL-DE-ALENQUER-PA-20.11.1996.pdf.

Acesso em 28/12/2018.

ONU MULHERES. Mulheres quilombolas: liderança e resistência para combater a invisibilidade. 19 de setembro de 2017. Disponível em: http://www.onumulheres.org.br/noticias/mdulheres-quilombolas-lideranca-e-resistencia-paracombater-a-invisibilidade/. Acesso em: 25/12/2018.

PARÁ. Governo do Estado. Lei n. 7.113, de 19 de março de 2008. Dispõe sobre declarar como Patrimônio Cultural e Artístico do Estado do Pará a dança "MARAMBIRÉ" do município de Alenquer - Pa. In: Diário Oficial do Estado do Pará. Poder Executivo, Belém, PA, 24 mar. 2008. Executivo 1, p, 06. Disponível em: www.ioepa.com.br/pages/2008/03/24/2008.03.24.DOE_6.pdf. Acesso em: 19/05/2018.

QUEIROZ, W. Contribuições para a História de Alenquer. Alenquer: Edição do autor, 2017.

QUEIROZ, W. Nação Negra. Alenquer: Edição do autor, 2011.

SASSEN, S. Expulsões: brutalidade e complexidade na economia global. Rio de Janeiro/São Paulo: Paz e Terra, 2016. 
SOUZA, G. S. de; PEZZUTI, J. C. B. Breve Ensaio sobre a Lógica Subjetiva dos Povos e Comunidades Tradicionais Amazônidas. Novos Cadernos NAEA, Belém, v. 20, n. 2, p. 111126, mai/ago. 2017.

TEIXEIRA, L. C. L. Marambiré: o negro no folclore paraense. Belém: SECULT; FCPTN, 1989.

WOLKER, A. C. Pluralismo, Justiça e Legitimidade dos Novos Direitos. Revista Sequência, Florianópolis, n, 54, p. 95-106, jul. 2007. 